\title{
Non-Isothermal Separation Process of Two-Phase Mixture Water/Ultra-Viscous Heavy Oil by Hydrocyclone
}

\author{
Josedite Saraiva de Souza ${ }^{1}$, Fabiana Pimentel Macêdo Farias ${ }^{2}$, Ramdayal Swarnakar ${ }^{1}$, Severino \\ Rodrigues de Farias Neto ${ }^{1}$, Antonio Gilson Barbos de Lima ${ }^{3}$ \\ ${ }^{1}$ Department of Chemical Engineering, Center of Sciences and Technology, Federal University of Campina \\ Grande, Campina Grande, Paraiba, Brazil \\ ${ }^{2}$ Department of Technology and Development, Center for Sustainable Development of the \\ Semi-Arid (CDSA), Federal University of Campina Grande, Sumé, Paraiba, Brazil \\ ${ }^{3}$ Department of Mechanical Engineering, Center of Sciences and Technology, Federal University of Campina \\ Grande, Campina Grande, Paraiba, Brazil \\ E-mail:eng.josedite@hotmail.com,fariasn@deq.ufcg.edu.br,rdswarnakar@yahoo.com, \\ fabianapmf@msn.com,gilson@dem.ufcg.edu.br \\ Recieved July 6, 2011; revised July 20, 2011; accepted July 30, 2011
}

\begin{abstract}
Environmental agencies do not allow effluents, from the petroleum productions, which contain oil concentrations that exceed the amounts permitted by the regulations. In recent time heavy oil operating petroleum industries are generating oil/water mixture by products, which are difficult to separate. Industrially, hydrocyclone is generally used to separate oil from an oil/water mixture. This is due to its high performance of separation, low cost of installation and maintenance. In the present work, therefore, the thermal fluid dynamics of water/ultra-viscous heavy oil separation process in a hydrocyclone has been studied. A steady state mathematical model which simulates the performance of a non-isothermal separation process is presented. The Eulerian-Eulerian approach for the interface of the phases involved (water/ultra-viscous heavy-oil) is used and the two-phase flow is considered as incompressible, viscous and turbulent. For carrying out numerical solutions of the governing equations the CFX $11^{\circledR}$ commercial code was used. Results of the behavior of the two-fluid flow inside the hydrocyclone and separation efficiency are presented and analyzed. The role of the average temperature of the fluid, oil droplet diameter and the fluid mixture inlet velocity on the separation efficiency of the hydrocyclone are verified.
\end{abstract}

Keywords: Thermal Fluid Dynamics, Hydrocyclone, Two-Phase Flow, Simulation, Separation Efficiency

\section{Introduction}

Petroleum industry has produced a large quantity of water along with hydrocarbons from oil and gas fields all over the world. The produced water comes as a byproduct of petroleum production and requires to be separated efficiently. On offshore platforms, produced water can be discharged directly into the ocean provided the dispersed phase concentration of oil and grease is below a specified value, such as $29 \mathrm{ppm}$ in the Gulf of Mexico and $20 \mathrm{ppm}$ in Brazil. In Norway, the oil operators have agreed to implement a policy of zero harmful discharges in the environment.

A number of studies have been found in literature using cyclones or hydrocyclones in the two-phase separa- tion processes [1-4]. Hydrocyclones have been used for over a hundred years by chemical process industries. However, just from the 60's there has been an increase of its application in various other fields of technology and is, therefore, considered an equipment of great importance for separation processes. This has happened in virtue of its high processing capacity, less physical space needed for its installations, easiness of operation and cheaper maintenance. In this context, some important experimental results of field trial of a patented CANMET hydrocyclone have been reported [5]. Their hydrocyclone was designed to process the difficult-to-separate oily fluids which were generated by heavy oil operations in western Canada.

Despite the advantages and simplicity, the fluid dy- 
namic behavior in hydrocyclones is relatively complicated. This is due to the presence of air core, zones of flow reversion, regions of recirculation, high vortex preservation and high turbulence intensity, among others [6-8]. Hydrocyclone application, therefore, is limited for the particles and/or droplets bigger than $10 \mu \mathrm{m}[5,9]$.

The computational tool CFD (Computational Fluid Dynamics) provides a better understanding of the rotational turbulent flow in the interior of hydrocyclone [10-12]. It is a key tool for the modeling of the isothermal and non-isothermal fluid flow in a hydrocyclone. Despite of the its importance, few studies on numerical simulations of the thermal fluid dynamics of a hydrocyclone using CFD applied to petroleum industry are found. In this sense, Eulerian-Eulerian approach has been used to study the thermal effect of the involved phases: water (continuous phase) and oil (dispersed phase), in the performance of the numerical simulation. Besides, it is also a known fact that the high viscosity of heavy oils induces high pressure drop, when it is in direct contact with the walls of hydrocyclone and results in low separation efficiency $[5,9]$. For these reasons, in the present work, a numerical simulation of the influence of the temperature on the separation process of water/heavy oil mixture has been investigated.

\section{Mathematical Model}

Mathematical modeling is a physical representation of reality in the form of a set of consistent equations. In present work to represent thermo fluid dynamics of the separation of ultra-viscous heavy oil droplets from water, a multiphase flow model has been utilized. The multiphase flow in a hydrocyclone is governed by equations of general laws of conservation of mass, momentum and energy, which are reported in ANSYS CFX 11.0.

\subsection{Equation of Mass Conservation}

The mass conservation is given by (1)

$$
\frac{\partial}{\partial t}\left(f_{\alpha} \rho_{\alpha}\right)+\nabla \bullet\left(f_{\alpha} \rho_{\alpha} \boldsymbol{U}_{\alpha}\right)=S_{M S \alpha}+\sum_{\beta=1}^{N_{p}} \Gamma_{\alpha \beta}
$$

where the Greek sub-indices $\alpha$ and $\beta$ represent the involved phases of water/ultra-viscous heavy oil mixture, $f$, $\rho$, and $\boldsymbol{U}$ are respectively the volume fraction, density and vector velocity. For phase $\alpha$, the vector velocity is given by $\boldsymbol{U}_{\alpha}=(u, v, w)$. The term $S_{M S \alpha}$ describes mass source, $\Gamma_{\alpha \beta}$ is the mass transfer in the interface of two involved phases, $\alpha$ and $\beta . N_{p}$ is the number of phases [13]. In order to simplify the model and the solution of governing equations, the source term of mass, $S_{M S \alpha}$, and interfacial mass transfer, $\Gamma_{\alpha \beta}$, were not considered. Thus, (1) is reduced to (2):

$$
\frac{\partial}{\partial t}\left(f_{\alpha} \rho_{\alpha}\right)=-\nabla \bullet\left(f_{\alpha} \rho_{\alpha} \boldsymbol{U}_{\alpha}\right)
$$

\subsection{Equation of Momentum Conservation}

The linear momentum conservation for multiphase flow is defined by (3):

$$
\begin{aligned}
& \frac{\partial}{\partial t}\left(f_{\alpha} \rho_{\alpha} \boldsymbol{U}_{\alpha}\right)+\nabla \bullet\left[f_{\alpha}\left(\rho_{\alpha} \boldsymbol{U}_{\alpha} \otimes \boldsymbol{U}_{\alpha}\right)\right] \\
& =-f_{\alpha} \nabla p_{\alpha}+\boldsymbol{S}_{\boldsymbol{M} \alpha}+\boldsymbol{M}_{\alpha}+\nabla \bullet\left\{f_{\alpha} \mu_{\alpha}\left[\nabla \boldsymbol{U}_{\alpha}+\left(\nabla \boldsymbol{U}_{\alpha}\right)^{T}\right]\right\} \\
& \quad+\sum_{\beta=1}^{N_{p}}\left(\Gamma_{\alpha \beta}^{+} \boldsymbol{U}_{\beta}-\Gamma_{\beta \alpha}^{+} \boldsymbol{U}_{\alpha}\right)
\end{aligned}
$$

where $p$ is pressure, $\mathbf{S}_{\mathbf{M} \alpha}$ represent the external forces per unit volume that act on the system, $\Gamma_{\beta \alpha}^{+}$is the mass flow rate per unit volume of the phase $\beta$ for phase $\alpha$. $M_{\alpha}$ describes total force (forces of interfacial drag, of sustentation, of wall lubrication, of virtual mass and of turbulent dispersion) per unit volume on continuous phase, which occurs due to the interaction with a dispersed phase, $\beta$.

In present work the interfacial mass transfer wasn't considered, hence the equation of momentum gets simplified to (4).

$$
\begin{aligned}
& \frac{\partial}{\partial t}\left(f_{\alpha} \rho_{\alpha} \boldsymbol{U}_{\alpha}\right)+\nabla \bullet\left[f_{\alpha}\left(\rho_{\alpha} \boldsymbol{U}_{\alpha} \otimes \boldsymbol{U}_{\alpha}\right)\right] \\
& =-f_{\alpha} \nabla p_{\alpha}+\boldsymbol{M}_{\alpha}+\nabla \bullet\left\{f_{\alpha} \mu_{\alpha}\left[\nabla \boldsymbol{U}_{\alpha}+\left(\nabla \boldsymbol{U}_{\alpha}\right)^{T}\right]\right\}
\end{aligned}
$$

The total force on phase $\alpha$ due to interaction with other phase $\left(M_{\alpha}\right)$ is given by (5):

$$
\boldsymbol{M}_{\alpha}=\sum_{\beta \neq \alpha} \boldsymbol{M}_{\alpha \beta}
$$

In this work only interfacial drag force was considered. The drag force of continuous phase, $\alpha$, due to phase $\beta$ is given by (6).

$$
\boldsymbol{M}_{\alpha \beta}=c_{\alpha \beta}^{(d)}\left(\boldsymbol{U}_{\beta}-\boldsymbol{U}_{\alpha}\right)
$$

where coefficient $c_{\alpha \beta}^{(d)}$ is computed by (7).

$$
c_{\alpha \beta}^{(d)}=\frac{3}{4} \frac{C_{D}}{d_{p}} f_{\beta} \rho_{\alpha}\left|\boldsymbol{U}_{\beta}-\boldsymbol{U}_{\alpha}\right|
$$

where $d_{p}$ is the particle diameter and $C_{D}$ is the drag coefficient. In this work, $C_{D}$ has been adopted to be equal to 0.44 (for the turbulent and viscous regime).

\subsection{Equation of Energy Conservation}

Conservation of energy is represented by (8). 


$$
\begin{aligned}
& \frac{\partial}{\partial t}\left(f_{\alpha} \rho_{\alpha} h_{\alpha}\right)+\nabla \bullet\left[f_{\alpha}\left(\rho_{\alpha} U_{\alpha} h_{\alpha}-\lambda_{\alpha} \nabla T_{\alpha}\right)\right] \\
& =\sum_{\beta=1}^{N p}\left(\Gamma_{\alpha \beta}^{+} h_{\beta s}-\Gamma_{\beta \alpha}^{+} h_{\alpha s}\right)+Q_{\alpha}+S_{\alpha}
\end{aligned}
$$

where $h_{\alpha}, T_{\alpha}$ and $\lambda_{\alpha}$, denote the static enthalpy, temperature and thermal conductivity of phase $\alpha$, respectively and $\mathrm{S}_{\alpha}$, describes the external sources of heat. The term $\left(\Gamma_{\alpha \beta}^{+} h_{\beta s}-\Gamma_{\beta \alpha}^{+} h_{\alpha s}\right)$ represents the heat transfer induced by mass transfer in the interface of the involved phases. In this work, the term of heat transfer induced by mass transfer at the interface and the energy source term, $S_{\alpha}$, have not been considered. This means that there is no chemical reaction in the present separation process. With these conditions the equation of energy gets transformed in (9):

$$
\frac{\partial}{\partial t}\left(f_{\alpha} \rho_{\alpha} h_{\alpha}\right)=Q_{\alpha}-\nabla \bullet\left[f_{\alpha}\left(\rho_{\alpha} \boldsymbol{U}_{\alpha} h_{\alpha}-\lambda_{\alpha} \nabla T_{\alpha}\right)\right]
$$

where $Q_{\alpha}$ denotes heat transfer at the interface, from one phase to another phase, given by $(10,11,12)$.

$$
Q_{\alpha \beta}=\sum_{\beta \neq \alpha} Q_{\alpha \beta}
$$

being

$$
Q_{\alpha \beta}=-Q_{\beta \alpha}
$$

and

$$
\sum_{\alpha} Q_{\alpha}=0
$$

Heat transfer across a phase boundary is usually described in terms of an overall heat transfer coefficient $h_{\alpha \beta}$, which is the amount of heat energy crossing a unit area per unit time per unit temperature difference between the phases. Thus, the rate of heat transfer, $Q_{\alpha \beta}$, per unit time across a phase boundary of interfacial area per unit volume $A_{\alpha \beta}$, from phase $\beta$, to phase $\alpha$, is:

$$
Q_{\alpha \beta}=h_{\alpha \beta} A_{\alpha \beta}\left(T_{\beta}-T_{\alpha}\right)
$$

This may be written in a form analogous to momentum transfer like that:

$$
Q_{\alpha \beta}=c_{\alpha \beta}^{(h)}\left(T_{\beta}-T_{\alpha}\right)
$$

where the volumetric heat transfer coefficient, $c_{\alpha \beta}^{(h)}$, is modeled using the correlations described below.

$$
c_{\alpha \beta}^{(h)}=h_{\alpha \beta} A_{\alpha \beta}
$$

Hence, the interfacial area per unit volume and the heat transfer coefficient, $h_{\alpha \beta}$, are required. It is often convenient to express the heat transfer coefficient in terms of a dimensionless Nusselt number:

$$
h_{\alpha \beta}=\frac{\lambda_{\alpha} N u_{\alpha \beta}}{d_{\beta}}
$$

In the particle model, the thermal conductivity scale, $\lambda_{\alpha}$, is taken to be the thermal conductivity of the continuous phase (water), and the length scale, $d_{\alpha}$, is taken to be the mean diameter of the dispersed phase (oil). For the convective heat transfer an empirical correlation (Ranz-Marshall) in (16), has been used. It is available in ANSYS CFX and is based on the theory of boundary layer for a steady flow, incompressible Newtonian fluid and spherical particles.

$$
N u=2+0.6 \operatorname{Re}^{0.5} \operatorname{Pr}^{0.3}
$$

where $N u$ and $R e$ are the Nusselt and Particles Reynolds numbers. This correlation is valid for $0<R e<200$ and $0<P_{r}<250$.

The Prandtl number $\left(P_{r}\right)$ is the ratio of the diffusivity of momentum and thermal diffusivity, defined by (18):

$$
\operatorname{Pr}=\frac{C_{p} \mu_{\alpha}}{\lambda_{\alpha}}
$$

where $C_{p}$ is the heat capacity and $\mu_{\alpha}$ the viscosity of the continuous phase (water).

\subsection{Turbulence Model}

Due to complexity of the turbulent fluid flow inside the hydrocyclone we use $k$ - $\varepsilon$ model (RNG) to complete the mathematical formulation. The renormalization group (RNG) $k-\varepsilon$ model is similar in form to the $k-\varepsilon$ model but includes additional terms for turbulence dissipation rate $\varepsilon$, furnishing more accurate predictions of the flow situations, including, separation process, streamlines, curves and stagnant regions.

The values of turbulent kinetic energy, $k$, and turbulent dissipation rate, $\varepsilon$, are directly obtained from the differential equations of transport as can be observed in (19) and (20):

$$
\frac{\partial}{\partial t}(\rho k)+\nabla \bullet(\rho \boldsymbol{U} k)=P_{k}-\rho \varepsilon+\nabla \bullet\left[\left(\mu+\frac{\mu_{t}}{\sigma_{k R N G}}\right) \nabla k\right]
$$

$$
\begin{aligned}
& \frac{\partial}{\partial t}(\rho \varepsilon)+\nabla \bullet(\rho \boldsymbol{U} \varepsilon) \\
& =\nabla \bullet\left[\left(\mu+\frac{\mu_{t}}{\sigma_{\varepsilon R N G}}\right) \nabla \varepsilon\right]+\frac{\varepsilon}{k}\left(C_{\varepsilon 1 R N G} P_{k}-C_{\varepsilon 2 R N G} \rho \varepsilon\right)
\end{aligned}
$$

where $\mu$ is the dynamic viscosity, $\rho$ is the density and $\mu_{t}$ is the turbulent viscosity which is given by (21). 


$$
\mu_{t}=C_{\mu} \rho \frac{k^{2}}{\varepsilon}
$$

where $C_{\mu}$ is an empirical constant, and the values of the constants are given by:

$$
C_{\mu}=\sigma_{k N R G}=\sigma_{\varepsilon N R G}=0.7179
$$

and

$$
\begin{gathered}
C_{\varepsilon 2 R N G}=1.68 \\
C_{\varepsilon 1 R N G}=1.42-\frac{\eta\left(1-\frac{\eta}{4.38}\right)}{1+\eta^{3} \beta_{R N G}}
\end{gathered}
$$

where,

$$
\eta=\sqrt{\frac{P_{k}}{\rho \varepsilon C_{\mu R N G}}}
$$

In this equation $P_{k}$ is the turbulence production due to viscous and buoyancy forces or shear production of turbulence, which is modeled using (26):

$$
P_{k}=\mu_{t} \nabla \boldsymbol{U} \bullet\left(\nabla \boldsymbol{U}+\nabla \boldsymbol{U}^{T}\right)+P_{k b}
$$

The term $P_{k b}$ is the production of buoyancy and is modelled by (27) as follows:

$$
P_{k b}=-\frac{\mu_{t}}{\rho \sigma_{p}} g \nabla \rho
$$

where $\sigma_{p}$ is a constant and is equal to 1 .

\subsection{Boundary Conditions}

The following boundary conditions, for the study of hydrocyclone, were used:

1) Inlet conditions $[5,9]$ :

\section{Water}

$u_{x}=20.0$ and $30.0 \mathrm{~m} / \mathrm{s}$

$u_{y}=u_{z}=0.0 \mathrm{~m} / \mathrm{s}$

$\mathrm{T}_{\text {inlet }}=298.0 \mathrm{~K}$

$f_{w}=0.7$

\section{Oil}

$u_{x}=20.0$ and $30.0 \mathrm{~m} / \mathrm{s}$

$u_{y}=u_{z}=0.0 \mathrm{~m} / \mathrm{s}$

$\mathrm{T}_{\text {inlet }}=298.0 \mathrm{~K}$

$f_{o}=0.3$

2) Outlet conditions:

A predefined pressure value 1 atm $(p=101325 \mathrm{~Pa})$ was adopted at overflow and underflow positions of the hydrocyclone.

3) Conditions at the wall:

- At internal walls of the hydrocyclone, all speed components $\left(u_{x}, u_{y}, u_{z}\right)$, for water and heavy oil phases, were considered to be null (no slip condition);
- A wall roughness of $0.045 \mathrm{~mm}$ in hydrocyclone was adopted;

- The hydrocyclone wall temperature chosen was $\mathrm{T}_{\text {wall }}$ $=673 \mathrm{~K}$.

In Table 1 the physical properties relating to the fluids (water and ultra-viscous heavy oil), used in this study, are shown. For the dynamic viscosity of the oil as a function of temperature a numerical fit with experimental data of [14] was made. It generated an equation which is presented in the Table 2 . The average viscosity of the heavy oil was calculated by the weighed mean of viscosity as a function of the temperature, for the interval of 298 to $673 \mathrm{~K}$, which are temperatures at inlet, $\mathrm{T}_{\min }$, and at wall, $\mathrm{T}_{\max }$, respectively. Thus, an average value of 1.2 Pa.s was obtained (28 and 29), which is within the range

Table 1. Data used in the simulation. Viscosity, considered as independent of the temperature variation.

\begin{tabular}{cccccccc}
\hline Cases & $f_{\text {oil }}$ & $\begin{array}{c}u_{x} \\
(\mathrm{~m} / \mathrm{s})\end{array}$ & $\begin{array}{c}d_{\text {poil }} \\
\left(10^{-3} \mathrm{~m}\right)\end{array}$ & $\begin{array}{c}\mu_{\text {oil }} \\
(\mathrm{Pa} . \mathrm{s})\end{array}$ & $\begin{array}{c}\mu_{\text {water }} \\
(\mathrm{Pa} . \mathrm{s})\end{array}$ & $\begin{array}{c}\mathrm{T}_{\text {wall }} \\
(\mathrm{K})\end{array}$ & $\begin{array}{c}\mathrm{T}_{\text {inlet }} \\
(\mathrm{K})\end{array}$ \\
\hline 1a & 0.3 & 30.0 & 1.000 & 0.9466 & 1.2 & 673.0 & 298.0 \\
2a & 0.3 & 30.0 & 0.800 & 0.9466 & 1.2 & 673.0 & 298.0 \\
3a & 0.3 & 30.0 & 0.600 & 0.9466 & 1.2 & 673.0 & 298.0 \\
$4 \mathrm{a}$ & 0.3 & 30.0 & 0.400 & 0.9466 & 1.2 & 673.0 & 298.0 \\
$5 \mathrm{a}$ & 0.3 & 30.0 & 0.200 & 0.9466 & 1.2 & 673.0 & 298.0 \\
$6 \mathrm{a}$ & 0.3 & 30.0 & 0.100 & 0.9466 & 1.2 & 673.0 & 298.0 \\
$7 \mathrm{a}$ & 0.3 & 30.0 & 0.010 & 0.9466 & 1.2 & 673.0 & 298.0 \\
$8 \mathrm{a}$ & 0.3 & 30.0 & 0.001 & 0.9466 & 1.2 & 673.0 & 298.0 \\
9a & 0.3 & 20.0 & 1.000 & 0.9466 & 1.2 & 673.0 & 298.0 \\
$10 \mathrm{a}$ & 0.3 & 20.0 & 0.800 & 0.9466 & 1.2 & 673.0 & 298.0 \\
$11 \mathrm{a}$ & 0.3 & 20.0 & 0.600 & 0.9466 & 1.2 & 673.0 & 298.0 \\
$12 \mathrm{a}$ & 0.3 & 20.0 & 0.400 & 0.9466 & 1.2 & 673.0 & 298.0 \\
$13 \mathrm{a}$ & 0.3 & 20.0 & 0.200 & 0.9466 & 1.2 & 673.0 & 298.0 \\
$14 \mathrm{a}$ & 0.3 & 20.0 & 0.100 & 0.9466 & 1.2 & 673.0 & 298.0 \\
$15 \mathrm{a}$ & 0.3 & 20.0 & 0.010 & 0.9466 & 1.2 & 673.0 & 298.0 \\
\hline
\end{tabular}

Table 2. Data used in the simulation. Viscosity as a function of temperature.

\begin{tabular}{cccccccc}
\hline Cases & $f_{\text {oil }}$ & $\begin{array}{c}u_{x} \\
(\mathrm{~m} / \mathrm{s})\end{array}$ & $\begin{array}{c}d_{\text {p,oil }} \\
\left(10^{-3} \mathrm{~m}\right)\end{array}$ & $\begin{array}{c}\mu_{\text {oil }} \\
(\mathrm{Pa} . \mathrm{s})\end{array}$ & $\begin{array}{c}\mu_{\text {water }} \\
(\mathrm{Pa} . \mathrm{s})\end{array}$ & $\begin{array}{c}\mathrm{T}_{\text {wall }} \\
(\mathrm{K})\end{array}$ & $\begin{array}{c}\mathrm{T}_{\text {inlet }} \\
(\mathrm{K})\end{array}$ \\
\hline 1b & 0.3 & 30.0 & 1.000 & $*$ & $* *$ & 673.0 & 298.0 \\
2b & 0.3 & 30.0 & 0.800 & $*$ & $* *$ & 673.0 & 298.0 \\
3b & 0.3 & 30.0 & 0.600 & $*$ & $* *$ & 673.0 & 298.0 \\
4b & 0.3 & 30.0 & 0.400 & $*$ & $* *$ & 673.0 & 298.0 \\
5b & 0.3 & 30.0 & 0.200 & $*$ & $* *$ & 673.0 & 298.0 \\
6b & 0.3 & 30.0 & 0.100 & $*$ & $* *$ & 673.0 & 298.0 \\
7b & 0.3 & 30.0 & 0.010 & $*$ & $* *$ & 673.0 & 298.0 \\
8b & 0.3 & 30.0 & 0.001 & $*$ & $* *$ & 673.0 & 298.0 \\
9b & 0.3 & 20.0 & 1.000 & $*$ & $* *$ & 673.0 & 298.0 \\
$10 \mathrm{~b}$ & 0.3 & 20.0 & 0.800 & $*$ & $* *$ & 673.0 & 298.0 \\
$11 \mathrm{~b}$ & 0.3 & 20.0 & 0.600 & $*$ & $* *$ & 673.0 & 298.0 \\
$12 \mathrm{~b}$ & 0.3 & 20.0 & 0.400 & $*$ & $* *$ & 673.0 & 298.0 \\
$13 \mathrm{~b}$ & 0.3 & 20.0 & 0.200 & $*$ & $* *$ & 673.0 & 298.0 \\
$14 \mathrm{~b}$ & 0.3 & 20.0 & 0.100 & $*$ & $* *$ & 673.0 & 298.0 \\
$15 \mathrm{~b}$ & 0.3 & 20.0 & 0.010 & $*$ & $* *$ & 673.0 & 298.0 \\
\hline
\end{tabular}

*3.1871 exp $\left(-2.3935 \mathrm{~T}_{\mathrm{adm}} * *\right) ; * * 0.0009 \exp \left(-2.6890 \mathrm{~T}_{\mathrm{adm}} * * *\right)$;

*** $\mathrm{T}_{\text {adm }}=\frac{\left(\mathrm{T}-\mathrm{T}_{\text {min }}\right)}{\left(\mathrm{T}_{\text {max }}-\mathrm{T}_{\text {min }}\right)}$ where $\mathrm{T}_{\text {max }}=673 \mathrm{~K}$ and $\mathrm{T}_{\text {min }}=298 \mathrm{~K}$. 
of viscosity standards used in the heavy oil industry.

$$
\mu(\mathrm{T})=a_{1} \mathrm{e}^{-b_{1} \mathrm{~T}}
$$

and

$$
\mu_{\text {average }}=\frac{1}{\Delta \mathrm{T}} \int_{\mathrm{T}_{\min }}^{\mathrm{T}_{\max }} \mu(\mathrm{T}) \mathrm{dT}
$$

\subsection{Case Studies}

To evaluate the effect of operational conditions on the thermo fluid dynamic performance of the hydrocyclone, for the separation process of water and ultra-viscous heavy oil, different conditions were defined and the cases studied are shown in Tables $\mathbf{1}$ and $\mathbf{2}$.

The operational conditions varied were: inlet velocity, $u_{x}$, oil droplet diameter, $d_{p}$, and viscosity of fluids, $\mu$. These conditions were adjusted to optimize the efficiency of separation, $E$, which was calculated considering the mass flow of oil at the overflow, $W_{\text {overflow, and the }}$ mass flow of oil at the inlet, $W_{\text {inlet, }}(30)$ :

$$
E=\frac{W_{\text {overflow }}}{W_{\text {inlet }}}
$$

\subsection{Hydrocyclone Geometry and Numerical Mesh}

In this work a numerical mesh, generated in the module CFX-Build 5.5, representing the hydrocyclone was used. Figure 1 illustrates the details of the hydrocyclone and unstructured mesh constructed by 42.393 nodal points, and 228.219 elements tetrahedral, apart from the detail of the upper and lower regions.

\section{Results and Discussion}

The main results of the numerical simulation, for a steady, non-isothermal two-phase flow of water/ultraviscous heavy oil mixture, inside the hydrocyclone, are presented in this section. The simulations were conducted in the presence of heat transfer. The composition of the fluid at the entrance of the equipment was kept constant.

\subsection{Temperature Field}

Figure 2 shows the contours of temperature on the yz plane of the hydrocyclone, for different diameters of the oil droplets $\left(10^{-6}, 10^{-5}, 10^{-4}, 10^{-3} \mathrm{~m}\right)$, for the cases $1,6,7$ and 8 (Table 2), where the hydrocyclone walls were heated to a constant temperature of $673 \mathrm{~K}$, the water/heavy oil mixture feed temperature was $298 \mathrm{~K}$ and

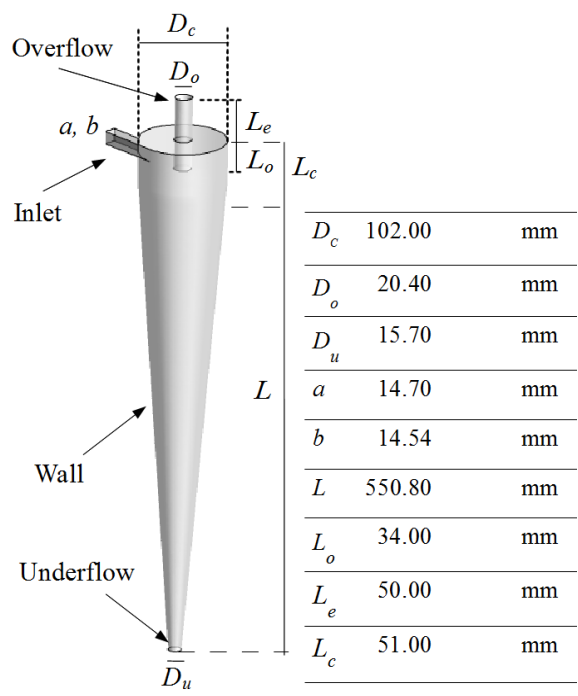

(a)

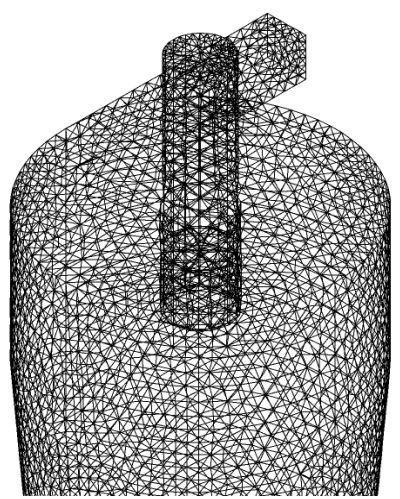

(b)



(c)
Figure 1. Geometrical representation of the hydrocyclone (a) Numerical mesh details, (b) top and (c) bottom.

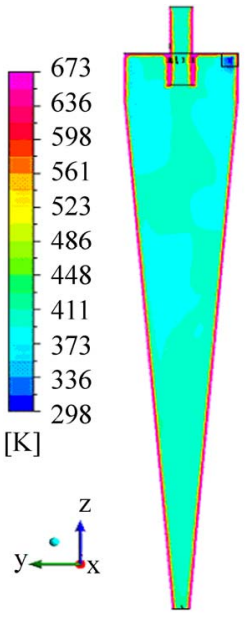

(a)

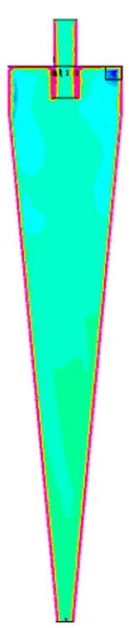

(b)

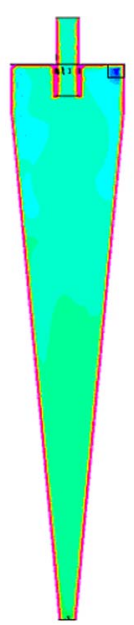

(c)



(d)
Figure 2. Temperature range of heavy-oil in the hydrocyclone yz plane, at fluid inlet velocity of $30 \mathrm{~m} / \mathrm{s}$ and diameters of the oil droplets, $d_{p}:$ (a) $1 \times 10^{-6} \mathrm{~m}$, (b) $1 \times 10^{-5} \mathrm{~m}$, (c) $1 \times$ $10^{-4} \mathrm{~m}$ and (d) $1 \times 10^{-3} \mathrm{~m}$. 
the viscosity was variable with the temperature.

It can be observed that these temperature fields present distinct behaviors. As such, the highest temperatures are in the neighborhoods of the equipment walls, facilitating the heat transference between fluid and the walls of the hydrocyclone [9]. The residence time of fluids in the device is low due to its length being $60 \mathrm{~cm}$ and the speed of mixture feed being $30 \mathrm{~m} / \mathrm{s}$.

Figure 3 presents the temperature profiles along the lines perpendicular to the duct entrance at four axial positions $(0.135,0.27,0.412$ and $0.550 \mathrm{~m})$. It can be observed that near the duct underflow position, $0.135 \mathrm{~m}$, the profile resembles the parabolic behavior, with the concave side up, because the temperature of the conical wall is warmer than the center of the hydrocyclone and the fluid flow is downward in this region. At the axial positions $0.275 \mathrm{~m}$ and $0.412 \mathrm{~m}$, the temperature profiles have approximately similar behavior, because the areas of recirculation and reverse flow present in this region and this is consistent with the literature $[1,11,15]$.

However, near the region of intersection between the conical and cylindrical sections $(0.550 \mathrm{~m})$, the temperature profile has the concave side down, which is due to the influence of oil currents circulating in this region and migrating to the outlet pipe near the overflow position.

In Figure 4 the effect of oil droplet diameter on the average temperature of the oil is presented. It can be seen that there is an increase in temperature across the yz plane with the increase in the diameter of the oil droplets. This is due to greater heat transfer in the larger oil droplets, which retains higher heat energy favoring an increase in the temperature from 389 to $405 \mathrm{~K}[5,16,17]$.

\subsection{Oil Streamline}

To verify the effect of the temperature on the fluid vis-

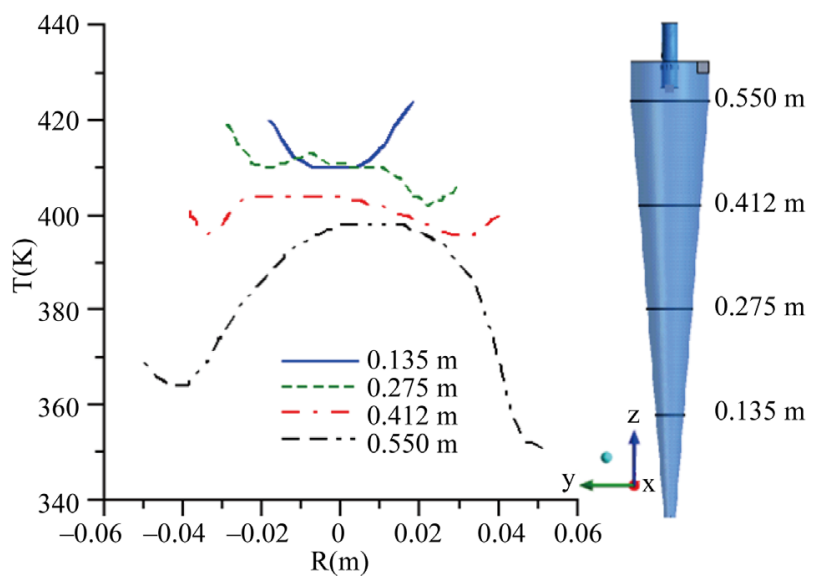

Figure 3. Temperature profiles at different axial positions, $R(m)$, along the hydrocyclone. Fluid inlet velocity $30 \mathrm{~m} / \mathrm{s}$ and oil droplet diameter of $10^{-3} \mathrm{~m}$.

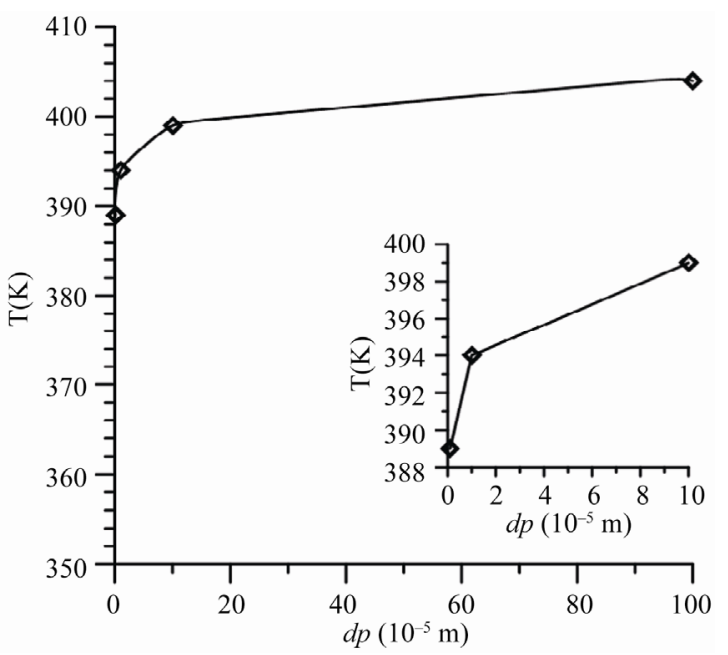

Figure 4. Heavy-oil temperature across the yz plane the as a function of diameter of oil droplets, $d_{p}$.

cosity, the fluid inlet velocity and the oil droplet diameter were fixed at $30 \mathrm{~m} / \mathrm{s}$ and $10^{-4} \mathrm{~m}$, respectively. Figure 5 illustrates this effect of temperature in the form of oil streamlines behavior in the hydrocyclone. Two situations were considered: in first case, Figure 5(a), the viscosity of the fluid was varied as a function of temperature, $\mu(\mathrm{T})$, and in the second case the oil viscosity was assumed to be constant and equal to 1.2 Pa.s, Figure 5(b).

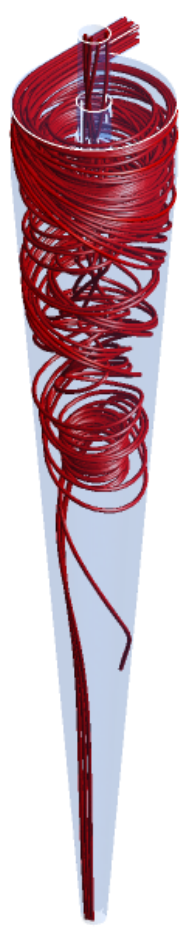

(a)



(b)
Figure 5. The oil streamlines for the inlet velocity of $30 \mathrm{~m} / \mathrm{s}$ and oil droplets diameter $10^{-4} \mathrm{~m}$. (a) $\mu(\mathrm{T})$ and (b) $\mu_{\text {average }}=$ 1.2 Pa.s. 
While comparing these two cases, it is found that the behavior of the streamlines is not the same. Thus, when oil viscosity varies as a function of the temperature, a differentiated behavior of the oil streamlines can be noticed. It is verified that the increase in temperature reduces the viscosity of the ultra-viscous heavy oil, and in consequence the number of recirculation of the streamlines, in the interior of hydrocyclone, increases. Therefore, the turbulence intensity, which is a ratio between the angular and axial momentum, in the interior of the device, increases. When the axial momentum is predominant, the circular movement of the streamlines disappears almost completely. This can be seen near to the underflow of the hydrocylone. Furthermore, as the gravitational force predominates, the more dense water stream leaves from the underflow and the less dense oil stream gets directed more to the overflow.

\subsection{Pressure Field}

In Figure 6 pressure fields on $x y$ plans, at position $\mathrm{z}$

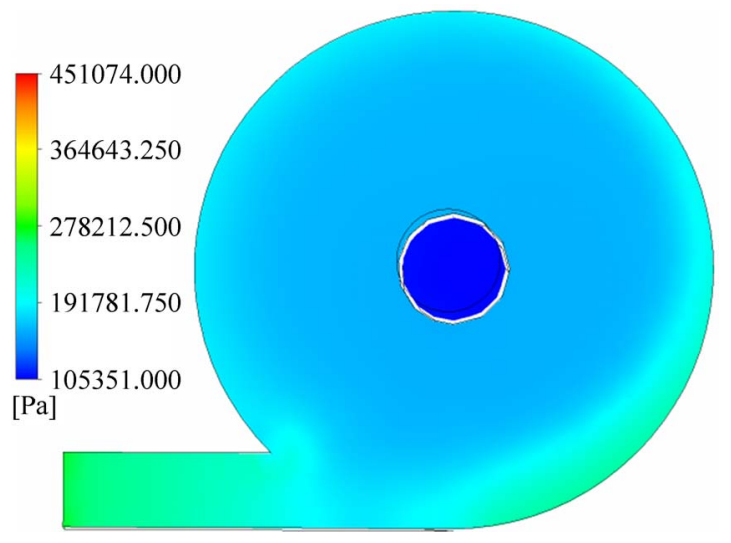

(a)

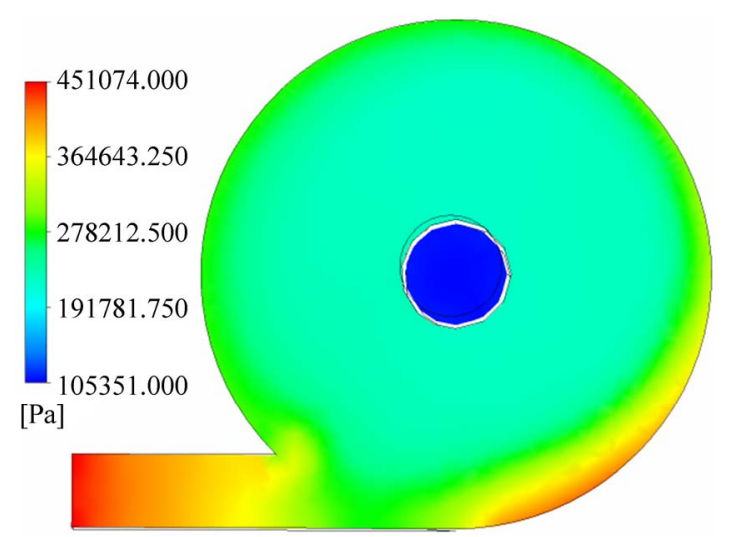

(b)

Figure 6. Pressure fields across the xy plans of the hydrocyclone axis, at $\mathrm{z}=\mathbf{0 . 6 0 0 3}$, for the fluid flow with $d_{p}=0.001$ $m$ and viscosity varying with temperature, for fluid inlet velocity: (a) $20 \mathrm{~m} / \mathrm{s}$ and (b) $30 \mathrm{~m} / \mathrm{s}$. equal to $0.6003 \mathrm{~m}$, are presented. It is possible to perceive regions of low pressure near the central axis of the hydrocyclone and high pressures in the regions near the walls and in the tangential entrance in the superior part of the hydrocyclone.

This behavior is attributed to the forces that are acting in these regions. At the entrance of the hydrocyclone, a drop pressure of $345723 \mathrm{~Pa}$, Figure 6(b), for the fluid speed of $30 \mathrm{~m} / \mathrm{s}$ and of $161082 \mathrm{~Pa}$, Figure 6(a), for 20 $\mathrm{m} / \mathrm{s}$, was observed. As it was expected, with the increase of the feed flow the pressure drop increased. Therefore, a greater consumption of energy for the pumping of the fluid mixture in the interior of the hydrocyclone is indicated.

\subsection{Oil Volume Fraction Field}

In Figure 7 the fields of the volumetric fraction of the dispersed phase (oil), on plan yz, for oil droplet diamers: $10^{-6}, 10^{-5}, 10^{-4}$ and $10^{-3} \mathrm{~m}$, are represented. As excted, a higher oil concentration in the neighborhoods of the hydrocyclone axis is verified. This fact is related with the difference of densities between oil and water. Further, it can also be observed that when the diameter of the oil droplets is bigger, the concentration of oil phase, near the hydrocyclone axis, is still higher, Figure 7(d).

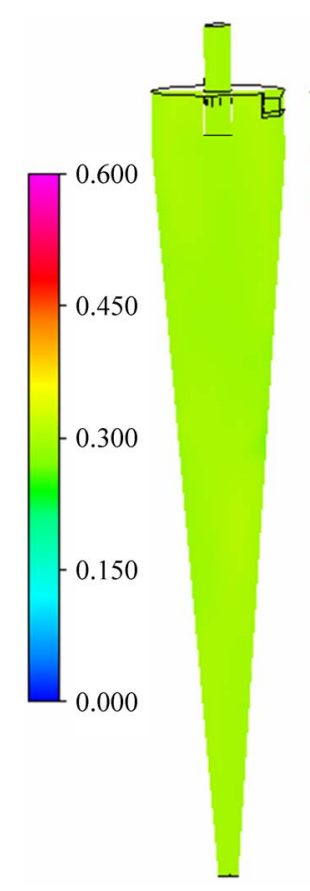

(a)

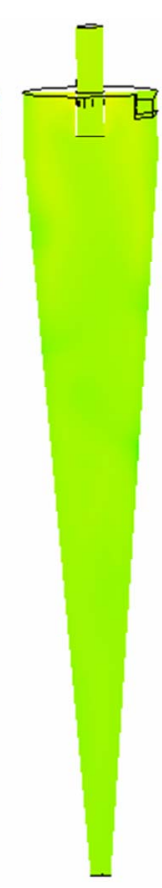

(b)

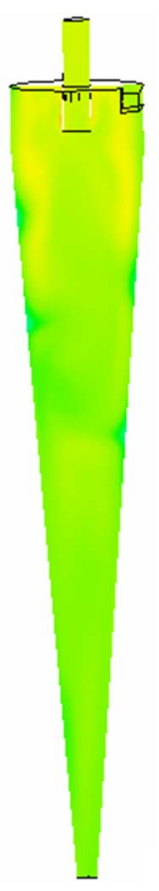

(c)



(d)
Figure 7. Oil volumetric fraction field of the dispersed phase (heavy oil) for fluid inlet velocity of $30 \mathrm{~m} / \mathrm{s}$ and oil droplet diameter, $d_{p}$ : (a) $1 \times 10^{-6} \mathrm{~m}$, (b) $1 \times 10^{-5} \mathrm{~m}$, (c) $1 \times$ $10^{-4} \mathrm{~m}$ and (d) $1 \times 10^{-3} \mathrm{~m}$. 


\subsection{Separation Efficiency}

In Figures 8 and 9 the numerical results of separation efficiency of the hydrocyclone, for the cases mentioned in Tables 1 and 2, are presented. To investigate the effect of fluid inlet velocity $(20 \mathrm{~m} / \mathrm{s}$ and $30 \mathrm{~m} / \mathrm{s})$, the average oil viscosity, was fixed at 1.2 Pa.s. It is observed that at higher inlet velocity of the mixture the separation efficiency was higher. This is in accordance with the results reported by in the literature $[3,18]$. For the case of bigger oil droplet diameter $(100 \mu \mathrm{m})$, it can be seen that the separation efficiency for water/ultra -viscous heavy oil increased from $62 \%$ to $66 \%$, when the inlet velocity of the fluids was increased from $20 \mathrm{~m} / \mathrm{s}$ to $30 \mathrm{~m} / \mathrm{s}$, respectively, (Figure 8).

With the objective of comparing the separation efficiency of the water/heavy oil mixture for the viscosity of oil being independent of the temperature, $\mu_{\text {average, and as }}$ dependent of temperature $\mu(\mathrm{T})$ results of the efficiency as a function of oil droplet diameter, are presented in Figure 9 . Here, the fluid inlet velocity was fixed at $20 \mathrm{~m} / \mathrm{s}$. For the case when the fluid viscosity variable with temperature it was verified that the separation efficiency, in general, increased for all the droplet diameters studied.

Moreover, it is observed that, this effect was more pronounced for greater droplet diameters [5]. Thus, it can be noticed that the difference in the separation efficiency between two cases for droplet diameter, smaller than 80 $\times 10^{-5} \mathrm{~m}$, was approximately $1 \%$ and for higher than size $80 \times 10^{-5} \mathrm{~m}$, it was about 4\% (Figure 9).

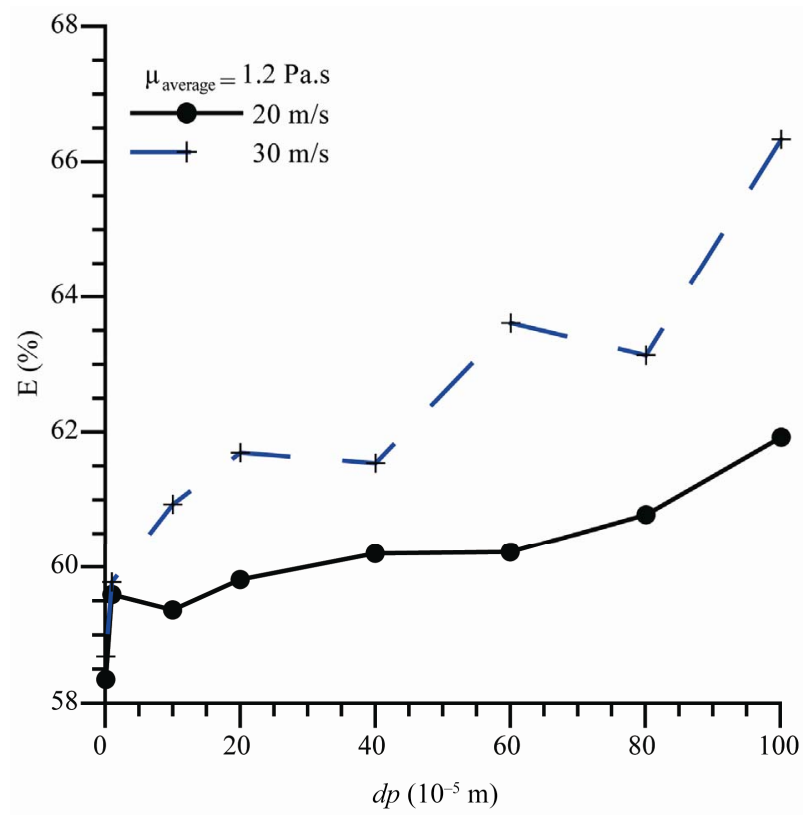

Figure 8. Separation efficiency for water/heavy oil, as a function of the oil droplet diameter.

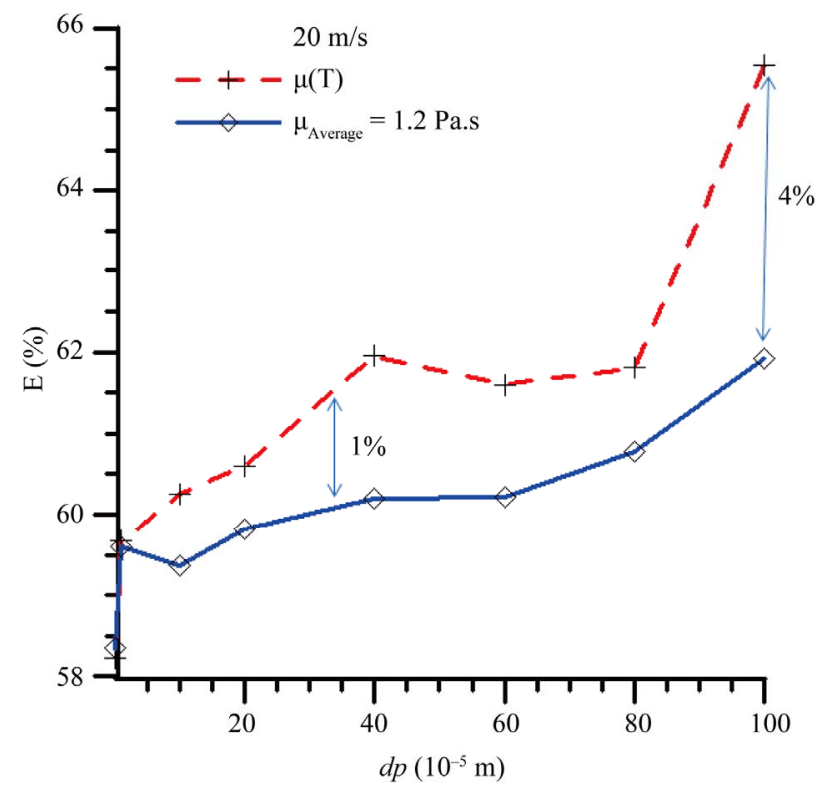

Figure 9. Separation efficiency for water/heavy oil as a function of the oil droplet diameter, for fluid inlet velocity of $20 \mathrm{~m} / \mathrm{s}$.

\section{Conclusions}

Based on the results of numerical simulation of the separation of water/ ultra-viscous heavy oil via hydrocyclone the following conclusions can be made:

- The proposed mathematical model was able to predict the thermo fluid dynamics for the separation process of water and ultra-viscous heavy oil mixture by hydrocyclone;

- The increase in the fluid temperature across the yz plane of the hydrocyclone was greater for the case of larger oil droplets diameter, because of the greater heat transfer capacity of the oil droplets;

- The number of recirculation of oil streamlines, in the interior of hydrocyclone, increased due to the increase in the average temperature of fluid inside the hydrocyclone;

- The pressure drop increased with the increase in the fluid inlet velocity in the hydrocyclone;

- A higher oil concentration in the neighborhoods of the hydrocyclone axis was verified;

- The separation efficiency was higher: 1) for higher fluid inlet velocity of the mixture, 2) when the average temperature of the fluid in the hydrocyclone was increased and 3) for bigger oil droplets size $\left(10^{-3} \mathrm{~m}\right)$.

\section{Acknowledgements}

The authors would like to express their thanks to CNPQ, CAPES, FINEP, ANP and JBR Engenharia Ltda. (Brazil), 
for supporting this work, and are also grateful to the authors cited in the text that helped in the improvement of quality.

\section{References}

[1] L. Svarovsky, "Solid-Liquid Separation, Chemical Engineering Series," 4th Edition, Butterworths, London, 2000.

[2] B. Wang and A. B. Yu, "Numerical Study of ParticleFluid Flow in Hydrocyclones with Different Body Dimensions," Minerals Engineering, Vol. 19, No. 10, 2006, pp. 1022-1033. doi:10.1016/j.mineng.2006.03.016

[3] T. Husveg, O. Rambeau, T. Drengstig and T. Bilstad, "Performance of Deoling Hydrocyclone during Variables Flow Rates," Minerals Engineering, Vol. 20, No. 4, 2007, pp. 368-379. doi:10.1016/j.mineng.2006.12.002

[4] L. G. M. Vieira, J. J. R. Damasceno and M. A. S. Barrozo, "Improvement of Hydrocyclone Separation Performance by Incorporating a Conical Filtering Wall," Chemical Engineering and Process, Vol. 49, No. 5, 2010, pp. 460467. doi:10.1016/j.cep.2010.03.011

[5] K. A. Hashmi, H. A. Hamza and J. C. Wilson, "CANMET Hydrocyclone: An Emerging Alternative for the Treatment of Oily Waste Streams," Minerals Engineering, Vol. 17, No. 5, 2004, pp. 643-649. doi:10.1016/j.mineng.2004.01.019

[6] V. Krishna, R. Sripriya, V. Kumar, S. Chakraborty and B. C. Meikap, "Identification and Prediction of Air Core Diameter in a Hydrocyclone by a Novel Online Sensor Based on Digital Signal Processing Technique," Chemical Engineering and Process, Vol. 49, No. 2, 2010, pp. 165-176. doi:10.1016/j.cep.2010.01.003

[7] M. J. Doby, A. F. Nowakowski, I. Yiu and T. Dyakowski, "Understanding Air Core Formation in Hydrocyclones by Studying Pressure Distribution as a Function of Viscosity," Journal of Mineral Processing, Vol. 86, No. 1-4, 2008, pp. 18-25. doi:10.1016/j.minpro.2007.09.002

[8] P. Bamrungsri, C. Puprasert, C. Guigui, P. Marteil, P. Bréant and G. Hérbrad, "Development of a Simple Experimental Method for the Determination of the Liquid Field Velocity in Conical and Cylindrical Hydrocyclones," Minerals Engineering Research and Design, Vol.
86, No. 11, 2008, pp. 1263-1270.

[9] J. S. Souza, "Numerical Study of Thermo Fluid Dynamic Separation of Heavy Oils Oily Waters of a Stream by Hydrocyclone," Master's Thesis, Federal University of Campina Grande, Brazil, 2009.

[10] B. Wang, D. L. Xu, G. X. Xiao, W. E. K. Chu and A. B. $\mathrm{Yu}$, "Numerical Study of Gas-Solid Flow in a Cyclone Separator," Third International Conference on CFD in the Mineral and Process Industrial, Melbourne, 10-12 December 2003, pp. 371-376.

[11] M. Narasimha, M. Brennan and P. N. Holthman, "A Review of CFD Modeling for Performance Predictions of Hydrocyclone," Engineering Applications of Computational Fluid Mechanics, Vol. 1, No. 2, 2007, pp. 109-125.

[12] H. F. Meier and M. Mori, "Gas-Solid Flow in Cyclones: The Eulerian-Eulerian Approach," Computers Chemical Engineering, Vol. 22, Suppl. 1, 1998, pp. S641-S644. doi:10.1016/S0098-1354(98)00114-8

[13] ANSYS CFX, "User Manual Theory," USA, 2006.

[14] T. Babadagli and A. Al-Bemani, "Investigations on Matrix Recovery during Steam Injection into Heavy-Oil Containing Carbonate Rocks," Journal Petroleum SciO ence and Engineering, Vol. 58, No. 1-2, 2007, pp. 259274. doi:10.1016/j.petrol.2007.01.003

[15] R. B. Xiang and K. W. Lee, "Numerical Study of Flow Field in Cyclones of Different Height," Chemical Engineering and Process, Vol. 44, No. 8, 2005, pp. 877-883. doi:10.1016/j.cep.2004.09.006

[16] H. Yoshida, T. Takashina, K. Fukuia and T. Iwanaga, "Effect of Inlet Shape and Slurry Temperature on the Classification Performance of Hydrocyclones," Powder Technology, Vol. 140, No. 1-2, 2004, pp. 1-9. doi:10.1016/j.powtec.2003.12.006

[17] J. J. Cilliers, L. Diaz-Anadon and F. S. Wee, "Temperature, Classification and Dewatering in $10 \mathrm{~mm}$ Hydro-cyclones," Minerals Engineering, Vol. 17, No. 5, 2004, pp. 591-597. doi:10.1016/j.mineng.2003.11.022

[18] M. A. Bennett and R. A. Williams, "Monitoring the Operation of an Oil/Water Separator Using Impedance Tomography," Minerals Engineering, Vol. 17, No. 5, 2004, pp. 605-614. doi:10.1016/j.mineng.2004.01.021 